\title{
Состояние ценопопуляции Platanthera bifolia (L.) Rich. (Orchidaceae Juss.) на самозарастающем отвале горной породы
}

\section{The coenopopulation state of Platanthera bifolia (L.) Rich. (Orchidaceae) on self- growing rock dumps}

\author{
Романова Н. Г., Монгуш Б. О. \\ Romanova N. G., Mongush B. O. \\ Кемеровский государственный университет, г. Кемерово, Россия. E-mail: chatn@yandex.ru \\ Kemerovo State University, Kemerovo, Russia
}

\begin{abstract}
Peфepam. Впервые в Кемеровской области проведена оценка состояния ценопопуляции Platanthera bifolia (L.) Rich, произрастающей на отвале горной породы. Определены численность, плотность, возрастная и виталитетная структура. В формирующемся фитоценозе техногенного ландшафта данный вид реализует свою жизненную стратегию. В настоящее время ценопопуляция немногочисленна, растет групповыми скоплениями. Возрастной спектр соответствовал базовому, ценопопуляция инвазионная с недостаточным семенным возобновлением. Анализ значений демографических признаков показал, что ценопопуляция молодая, по классификации «дельта-омега» относится к переходной. Ценопопуляция по комплексу морфометрических признаков депрессивная.
\end{abstract}

Ключевые слова. Виталитет, возрастная структура, демографические признаки ценопопуляции, отвал горной породы, Platantera bifolia.

Summary. For the first time in the Kemerovo region the assessment of the state of coenopopulations of Platanthera bifolia (L.) Rich growing on a rock dump is carried out. Population, density, age and vitality structure was identified. This species implements its life strategy in the emerging phytocenosis of the technogenic landscape. Currently, cenopopulation is small; it grows with a group of clusters. The age spectrum corresponded to the basic one. Cenopopulation was characterized as invasive with the lack of seed renewal. Analysis of the values of demographic characteristics showed that coenopopulation is young, according to the classification "delta-omega" refers to the transition. Cenopopulation on the complex of morphometric signs is depressed.

Key words. Age structure, demographic characteristics, vitality structure of coenopopulation, Platantera bifolia, rock dump.

\section{Введение}

В настоящее время в Кемеровской области стремительным темпом растет площадь нарушенных земель в результате деятельности добывающей промышленности. Специалисты прогнозируют, что подавляющее число фитоценозов будет возникать при биологической рекультивации и самозарастании. Известно, что работы по рекультивации нарушенных земель проводятся в недостаточном объеме по разным причинам. В связи с этим становится актуальным использование природного потенциала растительности к самовосстановлению (Баранник, Николайченко, 2008). Горнопромышленные ландшафты рассматриваются как перспективные с точки зрения сохранения видов и биотопов (Манаков, Куприянов, 2009).

В формировании растительного покрова техногенных ландшафтов на определенном этапе могут принимать участие представители семейства орхидных (Стрельникова, Манаков 2010; Филимонова и др., 2014), несмотря на то, что в силу своих биологических особенностей являются очень уязвимым компонентом флоры. Расселению и развитию орхидных способствуют легкие пылеватые семена, которые могут разноситься ветром на большие расстояния, и отсутствие конкуренции в формирующихся фитоценозах (Стецук, 2010). Изучению состояния ценопопуляций растений, произрастающих на отва- 
лах горнопромышленных предприятий Кемеровской области, посвящено мало работ (Романова, 2015; Романова, Ажичакова, 2016; Валуева, Романова, 2018; Romanova, Olefirenko, 2018), а оценка состояния ценопопуляций орхидных не проводилась.

Цель данной работы - изучить состояние ценопопуляции любки двулистной на самозарастающем отвале горной породы.

Объект исследования - любка двулистная (Platanthera bifolia (L.) Rich) - многолетнее травянистое поликарпическое растение, образующее утолщенный веретеновидный, стеблекорневой тубероид (Ишкинина, Ишмуратова, 2007). Размножается семенами (Иванова, 1987; Татаренко, 1996). Мезофит. Сильный микотроф (Мамаев и др., 2004), в целом стенобионтный вид (Ишкинина, Ишмуратова, 2007).

По типу жизненной стратегии Platanthera bifolia относится к группе растений, сочетающих свойства эксплерентов и ценотических патиентов. Так, для нее показано увеличение численности и ускорение онтогенеза в нарушенных местообитаниях (Стецук, 2010). В базовом онтогенетическом спектре л. двулистной преобладают взрослые вегетативные особи, при этом отсутствует постгенеративная фракция, тем не менее, такой спектр считается полночленным (Виляева, 2014).

В Кемеровской области встречается во всех районах в характерных местообитаниях - заросли кустарников, леса, лесные поляны и луга (Определитель растений Кемеровской..., 2001).

Как и многие виды семейства орхидные, P. bifolia является редким и охраняемым видом на территории России и Украины (Platanthera bifolia, 2019). Тем не менее в последнее время вид выводили из списков охраняемых видов ряда регионов, в том числе Кемеровской области (Красная книга республики..., 2001; Приказ Департамента Смоленской..., 2012; Красная книга Кемеровской..., 2012) из-за повсеместной встречаемости.

\section{Место и условия}

Место проведения исследований - окр. посёлка Привольный, в 5 км на север от городской черты г. Кемерово, правый берег р. Чесноковки. Изучаемая ценопопуляция P. bifolia располагалась вдоль основания (полосой длиной около 160 м и шириной 3 м) склона южной экспозиции отвала горной породы, отсыпанного на правом берегу р. Чесноковки вдоль поймы. Породы отвала: песчаник, алевролит, аргиллит, суглинки и глина. Почва низкогумусная, слабокислая. Содержание нитратного азота и подвижного фосфора в ней низкое, подвижного калия - повышенное. Превышений ПДК/ОДК химических веществ в исследованной почве не обнаружено. Верхняя часть отвала рекультивировалась в 1980-х гг. $\mathrm{XX}$ в. Зарастание нижней части отвала осуществляется в основном за счёт заноса семян из окружающих его лесов и заболоченных территорий, при этом антропогенное влияние на процесс самозарастания минимально.

Формирующийся фитоценоз в месте исследования представляет собой молодой смешанный разнотравный лес с невысокой степенью проективного покрытия (10-40 \%) и сомкнутости крон $(0,3-$ $0,6)$. Выражен слой листового опада $(4-5$ см), что благоприятствует произрастанию видов семейства Orchidaceae в растительных сообществах, формирующихся на промышленных отвалах (Филимонова и др., 2014).

\section{Материал и методы}

Материал для оценки состояния ценопопуляции объекта исследования собирали в 2018 г. в первой декаде июля. Изучаемые параметры: площадь, численность, плотность, возрастная и виталитетная структура. Счетная единица - особь.

Возрастные состояния идентифицировали по Р. М. Ишкининой, М. М. Ишмуратовой (2007). В возрастных спектрах вслед за Е. И. Филимоновой с соавторами (2014) не учитывали проростки. Тип популяции по классификации $\Delta-\omega$ интерпретировали по Л. А. Животовскому (2001) с рекомендуемыми поправками Виляевой Н. А. (2014) для популяций, в которых отсутствуют субсенильные и сенильные особи. Демографические индексы рассчитывали по Л. А. Жуковой (1987).

Виталитет определяли по методике Ю. А. Злобина с соавторами (2013) по следующим морфометрическим признакам: высота генеративного побега до соцветия (высота побега), длина соцветия, ширина и длина наиболее крупного листа (нижнего). 
Математическую обработку данных проводили в программе Statistica 6,0 с использованием пакета программ описательной статистики и однофакторного дисперсионного анализа. Достоверность отличий определяли по критерию Тьюки. Также оценивали долю влияния фактора «площадка» как отношение суммарной дисперсии фактора к общей суммарной дисперсии, умноженное на 100 \%.

\section{Результаты и их обсуждение}

На исследуемой территории было обнаружено 7 групповых скоплений (площадок) вегетативных и генеративных особей P. bifolia. Группы встречались на расстоянии от 5 до 60 м друг от друга. Генеративные особи цвели и плодоносили (табл. 1).

Таблица 1

Характеристика групповых скоплений в ценопопуляции P. bifolia

\begin{tabular}{|c|c|c|c|}
\hline № площадки & Площадь, ${ }^{2}$ & Число особей, шт. & Фенологическое состояние \\
\hline 1 & 26,5 & 43 & Цветение, плодоношение \\
\hline 2 & 5 & 40 & Цветение \\
\hline 3 & 1 & 4 & Цветение \\
\hline 4 & 1 & 1 & - \\
\hline 5 & 2 & 16 & Цветение, плодоношение \\
\hline 6 & 1 & 1 & Цветение, плодоношение \\
\hline 7 & 9 & 49 & \\
\hline всего & 43,5 & 154 & \\
\hline
\end{tabular}

Суммарная площадь скоплений составила 43,5 м². На этой площади всего насчитали 154 особи P. bifolia (невысокая численность). Для сравнения в формирующихся фитоценозах золоотвала Е. И. Филимонова с соавторами (2014) насчитывали 500-700 особей $P$. bifolia.

Значения демографических показателей исследуемой ценопопуляции приведены в таблице 2.

Таблица 2

Демографические показатели для исследуемых ценопопуляций P. bifolia

\begin{tabular}{|c|c|}
\hline Показатели & Значения \\
\hline Плотность (М), шт./M² & $0,3 \pm 0,13$ \\
\hline Эффективная плотность (М $)$, шт./м² & 0,16 \\
\hline $\begin{array}{l}\text { Соотношение возрастных групп, \%: } \\
(\mathrm{j}+\mathrm{im}+\mathrm{v}) \text { :g и тип ценопопуляции }\end{array}$ & $\begin{array}{c}68,8: 34,4 \\
\text { молодая }\end{array}$ \\
\hline Индекс восстановления $\left(\mathrm{I}_{\mathrm{p}}\right)$ & 2,0 \\
\hline Индекс замещения (I & 0,7 \\
\hline Индекс возрастности $(\Delta)$ & 0,22 \\
\hline Индекс эффективности $(\omega)$ & 0,52 \\
\hline Тип популяции по критерию «дельта-омега» & переходная \\
\hline
\end{tabular}

Общая и эффективная плотность ценопопуляции характеризовались невысокими значениями $\left(0,3\right.$ и 0,16 особей $/ \mathrm{M}^{2}$, соответственно). По соотношению возрастных групп ценопопуляцию можно отнести к молодой, что подтвердили значения индексов восстановления и замещения; по классификации «дельта-омега»- к переходной.

В возрастном спектре (рис.) ценопопуляции преобладали генеративные $(34,4 \%$ от общего числа особей) и имматурные особи (29,2 \%). Также высока доля виргинильных особей $(27,9 \%)$, а ювенильных - низкая $(8,4 \%)$.

Спектр характеризовался как двувершинный, полночленный с преобладанием взрослых особей прегенеративного периода. Эти данные соответствуют специфике базового спектра, хотя он может в разные годы сменяться на одновершинный. Низкий процент ювенильных особей в ценопопуляциях 


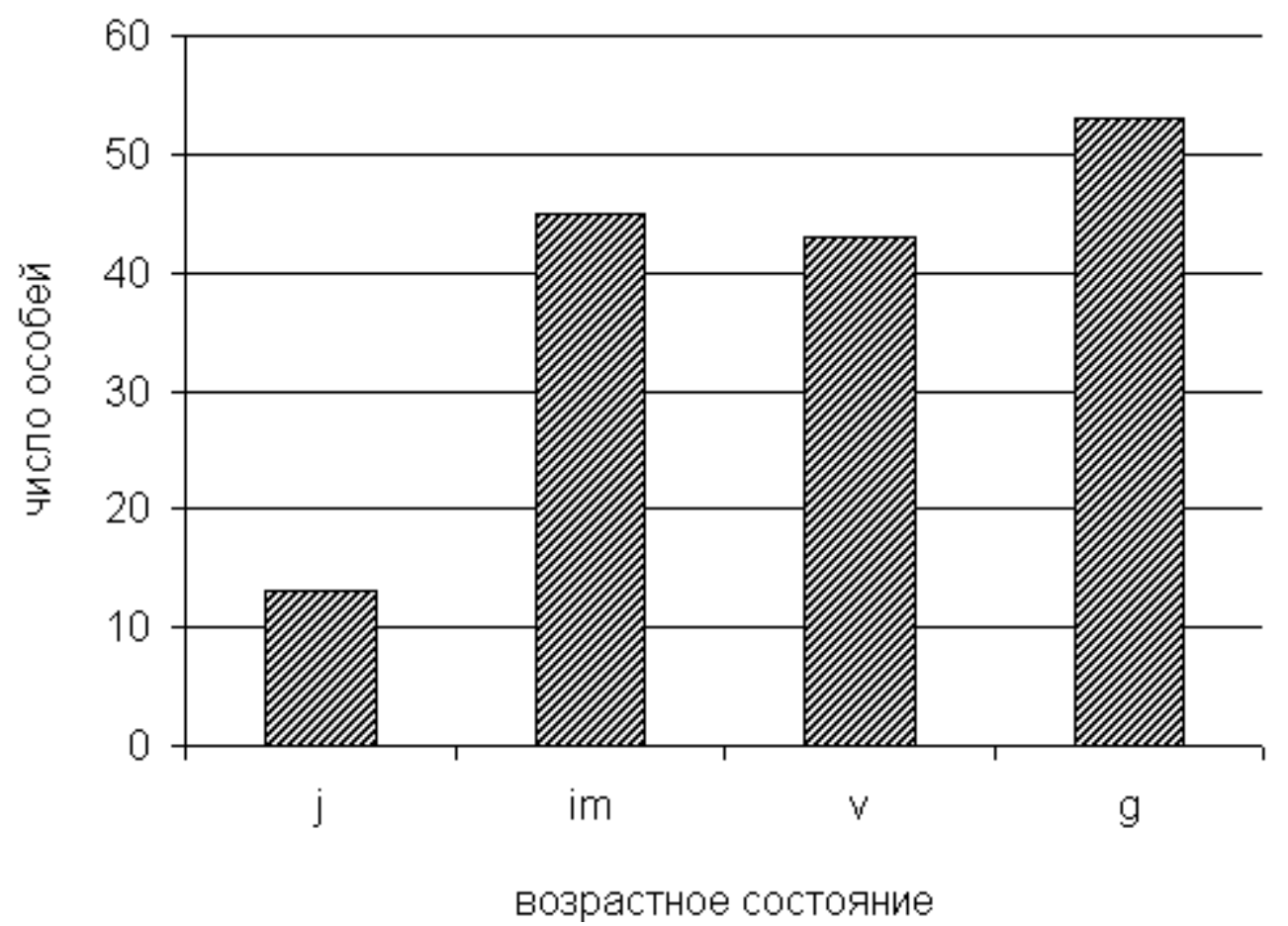

Рис. Возрастная структура ценопопуляции P. bifolia. Условные обозначения: $\mathrm{j}$ - ювенильные, im - имматурные, $\mathrm{v}$ - виргинильные, g - генеративные особи.

P. bifolia свидетельствует о недостаточном семенном возобновлении (Стецук, 2010; Филимонова и др., 2014).

Морфометрический анализ проводили у генеративных особей $P$. bifolia на площадках №№ 1, 2, 5 и 7, то есть там, где выборка была достаточной. Высота генеративных побегов варьировала от 12,5 до 49 см, в среднем составляла 32,5 см. Длина соцветий изменялась от 8,0 до 39,0 см, в среднем была 17,5 см. Дисперсионный анализ показал, что на первой площадке особи были достоверно выше. У исследованных побегов формировалось от 0 до 4 прицветных листьев. Длина самого крупного листа варьировала от 5,0 до 24,0 см, среднее значение - 17,1 см. Значения ширины самого крупного листа составили 2,9, 7,3 и 4,8 см, соответственно. По данным признакам у растений с разных площадок математический анализ не показал достоверных отличий. Доля влияния фактора «площадка» на изучаемые признаки составила в среднем $26 \%$.

В целом на площадке № 1 растения характеризовались более крупными размерами. Данная заросль самая большая по площади (табл. 1) и располагается среди наиболее старых деревьев в фитоценозе. Возможно, она появилась первой в данном местообитании и характеризуется наиболее благоприятными условиями обитания.

Для оценки жизненности ценопопуляции P. bifolia мы определяли средние значения исследуемых признаков у генеративных побегов в ценопопуляции в целом. Виталитетная структура ценопопуляции P. bifolia представлена в таблице 3.

Анализ показал, что в целом ценопопуляция P. bifolia являлась депрессивной, лишь по высоте генеративных побегов - равновесной.

Таким образом, в формирующемся фитоценозе в нижней части склона отвала горной породы ценопопуляция P. bifolia произрастает в соответствии со своей жизненной стратегией. В 2018 г. она характеризовалась невысокой численностью и плотностью. Возрастной спектр соответствовал базовому, ценопопуляция инвазионная с недостаточным семенным возобновлением. Анализ значений демографических признаков показал, что ценопопуляция молодая, по классификации «дельта-омега» относится к переходной. В целом в разных скоплениях на протяжении всей ценопопуляции P. bifolia не обнару- 
жено достоверных отличий между значениями морфометрических признаков генеративных растений, хотя в самой большой по площади заросли росли наиболее крупные особи. Виталитетный анализ показал, что данная ценопопуляция по комплексу морфометрических признаков депрессивная.

Таблица 3

Виталитетная стуктура ценопопуляции P. bifolia

\begin{tabular}{|c|c|c|c|c|c|}
\hline \multirow[t]{2}{*}{ Признак } & \multicolumn{3}{|c|}{$\begin{array}{c}\text { Доля счётных еди- } \\
\text { ниц когорты, \% }\end{array}$} & \multirow{2}{*}{$\begin{array}{c}\text { Индекс } \\
\text { качества, } \\
\text { Q }\end{array}$} & \multirow{2}{*}{$\begin{array}{c}\text { Тип } \\
\text { ценопопуляции }\end{array}$} \\
\hline & $\mathrm{a}$ & $\mathrm{b}$ & $\mathrm{c}$ & & \\
\hline Высота побега & 41,5 & 24,5 & 34,0 & 0,175 & Равновесная \\
\hline Высота соцветия & 37,7 & 17,0 & 45,2 & 0,145 & Депрессивная \\
\hline Число прицветных листьев & 20,8 & 40,0 & 40,0 & 0,160 & Депрессивная \\
\hline Длина листа & 32,1 & 20,8 & 47,2 & 0,140 & Депрессивная \\
\hline Ширина листа & 40,0 & 18,9 & 41,5 & 0,155 & Депрессивная \\
\hline В среднем & 34,4 & 24,2 & 41,5 & 0,155 & Депрессивная \\
\hline
\end{tabular}

\section{ЛИТЕРАТУРА}

Баранник Л. П., Николайченко В. П. Естественное лесовозобновление на отвалах угольных разрезов // Флора и растительность антропогенно нарушенных территорий: Сб. науч. тр. Кемеровского отделения РБО. - Кемерово: КРЭОО «Ирбис», 2008. - С. 12-16.

Валуева Д. С., Романова Н. Г. Число и завязываемость семян Fragaria vesca L. (Rosaceae) в зависимости от условий произрастания // Проблемы ботаники Южной Сибири и Монголии: Сб. науч. ст. по материалам XVII междунар. науч.-практ. конф. (24-27 мая 2018 г., г. Барнаул). - Барнаул: Изд-во АлтГУ, 2018. - С. 184-186.

Виляева Н. А. Состояние популяций Platanthera bifolia (L.) Rich. и Platanthera chlorantha (Cust.) Reichenb. (Orchidaceae) в национальном парке «Смоленское Поозерье» // Вестник Рос. ун-та дружбы народов. Сер. Экология и безопасность жизнедеятельности, 2014. - № 4. - С. 5-10.

Животовский Л. А. Онтогенетическое состояние, эффективная плотность и классификация популяций // Экология, 2001. - № 1. - С. 3-7.

Жукова Л. А. Динамика ценопопуляций луговых растений в естественных фитоценозах // Динамика ценопопуляций травянистых растений. - Киев: Наукова думка,1987. - С. 9-19.

Злобин Ю. А., Скляр В. Г., Клименко А. А. Популяции редких видов растений: теоретические основы и методика изучения. - Сумы: Университетская книга, 2013. - 439 с.

Иванова Е. В. Семейство Orchidaceae - Ятрышниковые, или Орхидные // Флора Сибири. Araceae-Orchidaсеае. - Новосибирск: Наука, 1987. - С. 125-146.

Иикинина Р. М., Иимуратова М. М. Онтогенез любки двулистной (Platantherabifolia (L.) L. C. Rich.) // Oнтогенетический атлас растений. - Йошкар-Ола: МарГУ, 2007. - Т. V. - 372 с.

Красная книга Кемеровской области: Т. 1. Редкие и находящиеся под угрозой исчезновения виды растений и грибов / Буко Т. Е., Горбунова И. А., Егоров А. Г. и др. - Кемерово: «Азия принт», 2012. - 208 с.

Красная книга Республики Башкортостан: в 2 т. Т. 1: Растения и грибы / Абрамова Л. М., Баишева Э. 3., Галеева А. Х. и др. - Уфа: МедиаПринт, 2011. - 384 с.

Мамаев С. А., Князев М. С., Куликов П. В., Филлипов Е. Г. Орхидные Урала: систематика, биология, охрана. - Екатеринбург: УрОРАН, 2004. - 123 с.

Манаков Ю. А., Куприянов $\boldsymbol{A}$. Н. Местообитания отвально-карьерных ландшафтов для охраны растений // Флора и растительность антропогенно нарушенных территорий: Сб. науч. тр. Кемеровского отделения РБО. - Кемерово: «Ирбис», 2009. - Вып. 5. - С 6-9.

Определитель растений Кемеровской области / И. М. Красноборов, Э. Д. Крапивкина, М. Н. Ломоносова и др. - Новосибирск: Изд-во СО РАН, 2001. - 477 с.

Приказ департамента Смоленской области по охране, контролю и регулированию использования животного мира и среды их обитания от 29.05.2012 № 119 «Об утверждении перечней (списков) видов грибов, лишайников и растений, занесенных в Красную книгу Смоленской области и исключенных из Красной книги Смоленской области (по состоянию на 1 марта 2012 г.)». 
Романова Н. Г. Структура ценопопуляций Fragaria vesca L. в различных местообитаниях // Проблемы ботаники Южной Сибири и Монголии: Сб. науч. ст. по материалам XIV междунар. науч.-практ. конф. (25-29 мая 2015 г., Барнаул). - Барнаул: Изд-во АлтГУ, 2015. - С. 291-294.

Романова Н. Г., Ажичакова $\boldsymbol{E}$. C. Особенности возрастной структуры ценопопуляций Fragaria vesca L. в техногенном ландшафте // Флора и растительность Сибири и Дальнего Востока: Чтения памяти Л. М. Черепнина и VI Всероссийская конф. с междунар. участием, посвящ. 110-летию со дня рождения Л. М. Черепнина и 80-летию Гербария им. Л. М. Черепнина (KRAS). - Красноярск, 2016. - С. 302-307.

Стецук Н. П. Экологические особенности Platanthera bifolia (L.) Rich. на территории Южного Приуралья // Вестник ОГУ, 2010. - № 6 (112). - С. 34-37.

Стрельникова T. О., Манаков Ю. А. Редкие и исчезающие виды растений Кемеровской области в техногенных ландшафтов Кузбасса // Флора и растительность антропогенно нарушенных территорий: Сб. науч. тр. Кемеровского отделения РБО. - Кемерово: «Ирбис», 2010. - Вып. 6. - С. 174-175.

Татаренко И. В. Орхидные России: жизненные формы, биология, вопросы охраны. - М.: Аргус, 1996. - 207 с.

Филимонова Е. И., Лукина Н. В., Глазырина М. А. Орхидные в техногенных экосистемах Урала // Экосистемы, их оптимизация и охрана. - Симферополь: ТНУ, 2014. - Вып. 11. - С. 68-75.

Platanthera bifolia (L.) Rich. // Плантариум. Определитель растений on-line. - 2019. - URL: http://www. plantarium.ru/page/view/item/28622.html, свободный.

Romanova N., Olefirenko I. Age structure of coenopopulation of Fragaria vesca L. in the natural and transformed habitats // BIO Web Conf., 2018. - Vol. 11. URL: https://www.bio-conferences.org/articles/bioconf/full_html/2018/02/ bioconf_pdcmb2018_00035/bioconf_pdcmb2018_00035.html 